\title{
The Ignition Parameter $\operatorname{Tn} \tau$ and the Energy Multiplication Factor $k$ for Fusioning Plasmas
}

J. Rand McNally, Jr. 


\section{DISCLAIMER}

This report was prepared as an account of work sponsored by an agency of the United States Government. Neither the United States Government nor any agency Thereof, nor any of their employees, makes any warranty, express or implied, or assumes any legal liability or responsibility for the accuracy, completeness, or usefulness of any information, apparatus, product, or process disclosed, or represents that its use would not infringe privately owned rights. Reference herein to any specific commercial product, process, or service by trade name, trademark, manufacturer, or otherwise does not necessarily constitute or imply its endorsement, recommendation, or favoring by the United States Government or any agency thereof. The views and opinions of authors expressed herein do not necessarily state or reflect those of the United States Government or any agency thereof. 


\section{DISCLAIMER}

Portions of this document may be illegible in electronic image products. Images are produced from the best available original document. 


\section{Printed in the United States of America. Available from National Technical Information Service \\ U.S. Department of Commerce \\ 5285 Port Royal Road, Springfield, Virginia 22161 \\ Price: Printed Copy $\$ 4.00$; Microfiche $\$ 3.00$}

This report was prepared as an account of work sponsored by the United States Government. Neither the United States nor the Energy Research and Development Administration/United States Nuclear Regulatory Commission, nor any of their employees, nor any of their contractors, subcontractors, or their employees, makes any warranty, express or implied, or assumes any legal liability or responsibility for the ar.r.uracy, completeness or usefulness of any information. apparatus. product or process disclosed, or represents that its use would not infringe privately owned rights. 
Contract No. W-7405-eng-26

FUSION ENERGY DIVISION

THE IGNITION PARAMETER Tn $\tau$ AND THE ENERGY MULTIPLICATION FACTOR $k$ FOR FUSIONING PLASMAS

J. Rand McNally, Jr.

To be submitted to Nuclear Fusion

Date Published - April 1977

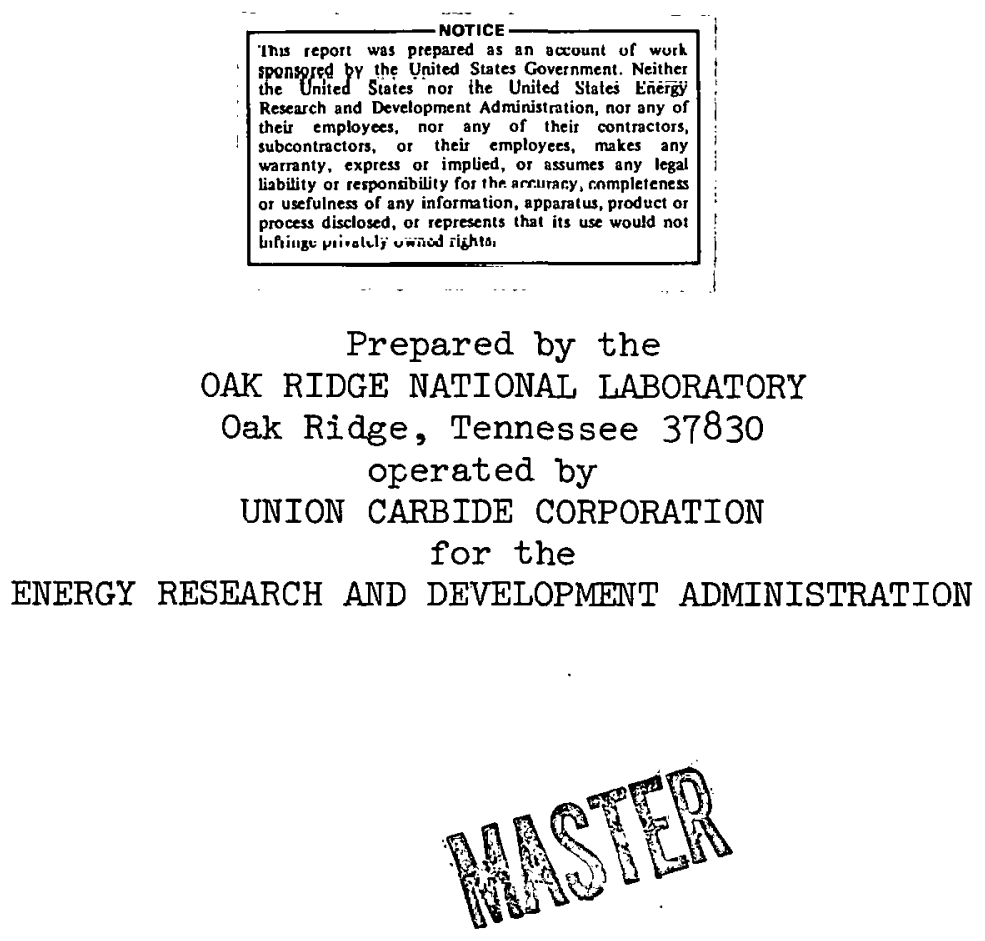


This paper presents some novel interpretations of fusion plasmas which may be of interest to both fission and fusion scientists and engineers. A new fusion ignition parameter $\left(\operatorname{Tn}_{e}{ }^{\tau}{ }_{E}\right)_{I}$ is proposed which is proportional to $B^{2} B^{4}$ and inversely proportional to the fusion power density ( $\mathrm{P}_{\text {Fusion }}$ ) of a reacting plasma. Curves are given for many potential nuclear fusion fuels. The energy utilization factor in existing devices is defined as $f=P_{\text {Fusion }} / P_{\text {Loss }}=\left(\operatorname{Tn}_{e} \tau_{L}\right) /\left(\operatorname{Tn}_{e} \tau_{E}\right)_{I}$; in experimental plasmas, $f$ has increased by about two orders of magnitude in the past decade and now exceeds $10^{-4}$ (a "nearest" $f^{*}$ exceeds $10^{-3}$ ). The $f$ factor is also analogous to its fission counterpart in the four-factor neutron multiplication factor $k=f j \varepsilon p$, where $f$ is the neutron thermal utilization factor. Past, present, and future fusion experiments are discussed briefly in this context. 
I. INTRODUCTION

The goal of scientific feasibility for controlled fusion research is to achieve in hydrogen plasma a plasma temperature $T$, electron density $n_{e}$, and energy confinement time $\tau_{E}$ which together satisfy conditions for igniting a DT plasma. The simple product $\operatorname{Tn} e^{\tau} \mathrm{L}$ for experimentally achieved plasmas is a very useful and meaningful criterion for evaluating the degree of closeness to achieving an ignition ( $\left(\mathrm{n}_{e} \tau_{E}\right.$ ) $I$ in at least an elementary way. Here, $\tau_{L}=$ net energy confinement time and $\tau_{E}$ is the energy confinement time for an ignited plasma.

The partial product $n_{\varepsilon} \tau_{E}$ used here differs from Lawson's $n \tau$ [1] in that the evaluation of a plasma ignition $n_{e}{ }^{\tau} E$ uses only the charged particle energy deposition in the plasma, although in dense pellet fusion some neutron energy deposition and neutron reactions may also be incorporated [2]. Lawson used both the charged particle energy contribution and that of the neutron (four times the energy of the alpha particle in the DT case) as well as bremsstrahlung radiation losses and a thermal energy recovery efficiency to give an energy break-even condition.

It is quite likely that magnetically confined fusioning plasmas must be ignited to ensure a reasonable economic return. Since ( $\left.\operatorname{Tn}_{e} \tau_{E}\right)_{I}$ is defined here as the "bare" or elemental value required to ignite the plasma over all energy losses, one has for the energy confinement time $\tau_{E}=1 / \Sigma\left(1 / \tau_{L}\right)=\Sigma\left(\frac{j}{2}\right) n_{k} T_{k} / P_{\text {Fusion }}$, where $k$ stands for both ions and electrons. For pure DT fuel, $\overline{\mathrm{T}}_{e}=\mathrm{T}_{i}$, and $\overline{\mathrm{P}}_{\text {Fugion }}=\mathrm{n}_{\mathrm{D}} \mathrm{n}_{\mathrm{T}}\left\langle\sigma v{ }_{\mathrm{DT}} \mathrm{Q}_{+}\right.$ the ignition parameter $\left(\mathrm{Tn}_{\mathrm{e}} \tau_{\mathrm{E}}\right)_{\mathrm{I}}$ becomes simply $12 \mathrm{~T}^{2} /\left(\langle\sigma \mathrm{V}\rangle \mathrm{DT}^{Q_{+}}\right.$) for $n_{D}=n_{T}$ and where the charged particle energy release is $Q_{+}=3520$ $\mathrm{keV}$ and $\mathrm{T}$ is in $\mathrm{keV}$.

The $T n_{e}{ }^{\tau} E$ product was apparently first proposed in 1973 [3]. It has two very important physical meanings: 1) the ignition parameter ( $\operatorname{Tn} e^{\tau} \mathrm{E}$ ) for a given fuel is inversely proportional to the fusion power density of the ignited plasma and hence its minimum value, for a given fuel, corresponds to the maximum fusion power density for that fuel $\mathrm{mix}$; and 2) the ratio of the experimentally achieved $\operatorname{Tn}_{e}{ }^{\tau} \mathrm{L}$ product to that required for "bare" ignition $\left(\mathrm{Tn}_{\mathrm{e}} \tau_{E}\right)_{I}$ is defined as the "energy utilization factor $f$," quite analogous to the "neutron thermal utiliza- 
tion factor $f^{\prime \prime}$ used in the neutron multiplication factor, $k=f \eta \varepsilon p$ for nuclear fission reactors [4]. Thus, the simple ignition parameter $\left(\operatorname{Tn} e^{\tau} E^{\prime} I\right.$ is only a first-cut at evaluating the plasma energy criticality or ignition. The physical interpretations of both ( $\operatorname{Tn} e_{E} \tau_{I}$ and $k_{\text {Fusion }}$ are the subjects of the next two sections. It. should be noted that while considerable progress has been made in recent years, presently achieved values of $\mathrm{f}$ for the fusion case are less than $10^{-3}$ and hence the $f$ factor dominates the fusion $k$ factor at the present time.

\section{THE IGNITION FEASTBILITY CRITERION, ( $\left.\operatorname{Tn}_{e}{ }^{\tau}{ }_{E}\right)_{I}$}

The general expression for the fusion ignition parameter is

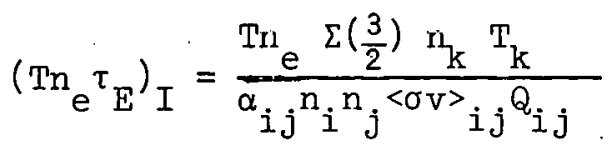

in $\mathrm{keV} \mathrm{cm}^{-3} \mathrm{sec}$

where $\alpha_{i j}=1$ for $i \neq j$ and $1 / 2$ for $i=j, n_{i}$ and $n_{j}$ are fuel ion densities, $Q_{i j}$ is the charged particle energy release in $\mathrm{keV}$ and $T$ is the plasma temperature in $\mathrm{keV}$. One obtains

$$
\left(\operatorname{Tn}_{e} \tau_{E}\right)_{I}= \begin{cases}\frac{\left(\frac{3}{2}\right) T^{2} n_{e}\left[n_{e}+\alpha_{i j}\left(n_{i}+n_{j}\right)+n_{x}\right]}{\alpha_{i j} n_{i} n_{j}\langle\sigma v\rangle_{i j} Q_{i j}} & \text { for } T_{e}=T_{i}=T \\ \frac{\left(\frac{3}{2}\right) T^{2} n_{e}\left[n_{1}+n_{j}+n_{x} / \alpha_{1 j}\right]}{n_{i} n_{j}\left\langle\sigma v>{ }_{i j} Q_{i j} \ldots\right.} & \text { for } T_{e}<<T_{i}=T\end{cases}
$$

Here, $x$ designates alphas and/or other impurities and $n_{e}=\alpha_{i j}\left(z_{i} n_{i}+\right.$ $\left.Z_{j} n_{j}\right)+\Sigma Z_{x} n_{x}$. Thus, $\left(T n_{e} \tau_{E}\right)_{I}$ is proportional to $T^{2} /\langle\sigma v\rangle_{i j}$ and is inversely proportional to the fusion power density as shown below.

The fusion power density is defined as

$P_{\text {Fusion }}=\alpha_{i j} n_{i} n_{j}^{\langle\sigma v\rangle_{i j}} Q_{i j}$

and the plasma heta. is for $B$ in Tesla, $T$ in $\mathrm{keV}$ and $\mathrm{n}$ in $\mathrm{cm}^{-3}$

$B=\frac{8 \pi \sum n_{k} T_{k}\left(1.6 \times 10^{-17}\right)}{B^{2}}$ 
Thus, one obtains for $\mathrm{P}_{\text {Fusion }}$ now in watts $/ \mathrm{cm}^{3}$

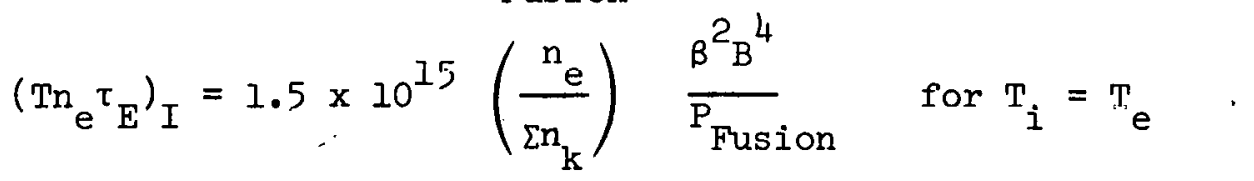

and for a given plasma $B$ and magnetic field $B$ the ignition criterion is inversely proportional to the fusion power density. In the case of pellet fusion $\left(\mathrm{Tn} \tau_{\mathrm{E}}\right)_{I} \propto \mathrm{p}^{2} / \mathrm{P}_{\text {Fusion }}$, where $\mathrm{p}$ is the plasma pressure (or the stored energy density).

The energy confinement time $\tau_{E}$ represents all energy losses such as those due to radiation (line, bremsstrahlung, and synchrotron), particle diffusion, charge exchange, conduction, convection, instabilities, etc. and $I / \tau_{E}=\Sigma I / \tau_{L}$ for ignition.

The principal fusion reactions with their $Q_{i j}=Q_{+}$values and the associated ignition parameter, assuming $\mathrm{n}_{\mathrm{x}}=0$ and $\mathrm{T}_{\mathbf{i}}=\mathrm{T}_{\text {e }}$, are:

$$
\begin{aligned}
& \mathrm{D}+\mathrm{T} \rightarrow \mathrm{n}+\alpha+3520 \mathrm{keV} \\
& \left.\left(\operatorname{Tn}_{e} \tau_{E}\right)_{D T}=12 T^{2} /(3520<\sigma V\rangle_{D T}\right) \\
& \text { for } D / T=1 \quad(I) \\
& D+D \rightarrow\left\{\begin{array}{l}
n+3 \mathrm{He}+800 \mathrm{keV} \\
\mathrm{p}+\mathrm{t}+4000 \mathrm{keV}
\end{array}\right. \\
& \left.\bar{Q}_{D D} \sim 2400 \mathrm{keV}\right\}(\Omega)
\end{aligned}
$$

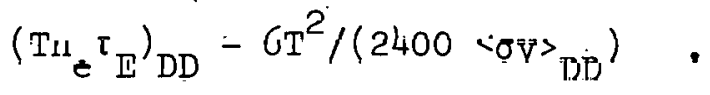

For catalyzed DD in which the $t$ and ${ }^{3}$ He are burned $100 \%$ with $D$ fuel

$$
\begin{aligned}
& 2 \mathrm{D}+4 \mathrm{D} \rightarrow 2 \mathrm{n}+2 \mathrm{p}+2 \alpha+13,400 \mathrm{keV} \\
& \left.\left(\operatorname{Tn}_{e} \tau_{E}\right)_{C A T D D}=6 T^{2} /(13,400<O V\rangle_{D D}\right) \\
& \mathrm{D}+3^{3} \mathrm{He} \rightarrow \mathrm{p}+\alpha+18,400 \mathrm{keV}
\end{aligned}
$$

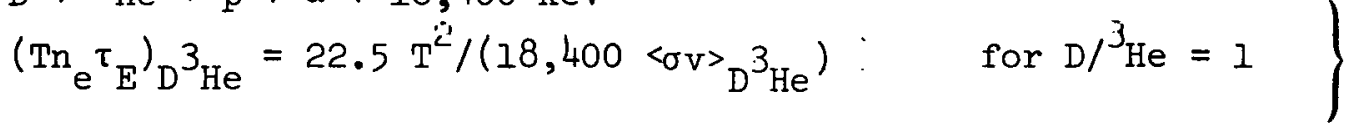

$$
\begin{aligned}
& 3 \mathrm{He}+3_{\mathrm{He}}+2 \mathrm{p}+\alpha+12,900 \mathrm{keV} \\
& \left(\mathrm{Tn}_{\mathrm{e}} \tau_{\mathrm{E}}\right) 3_{\mathrm{He}} 3_{\mathrm{He}}=18 \mathrm{~T}^{2} /\left(12,900<0 \mathrm{v}>3_{\mathrm{He}}{ }^{3} \mathrm{He}\right)
\end{aligned}
$$




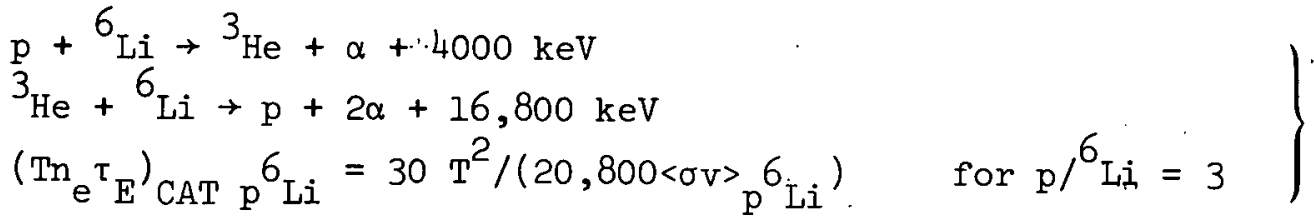

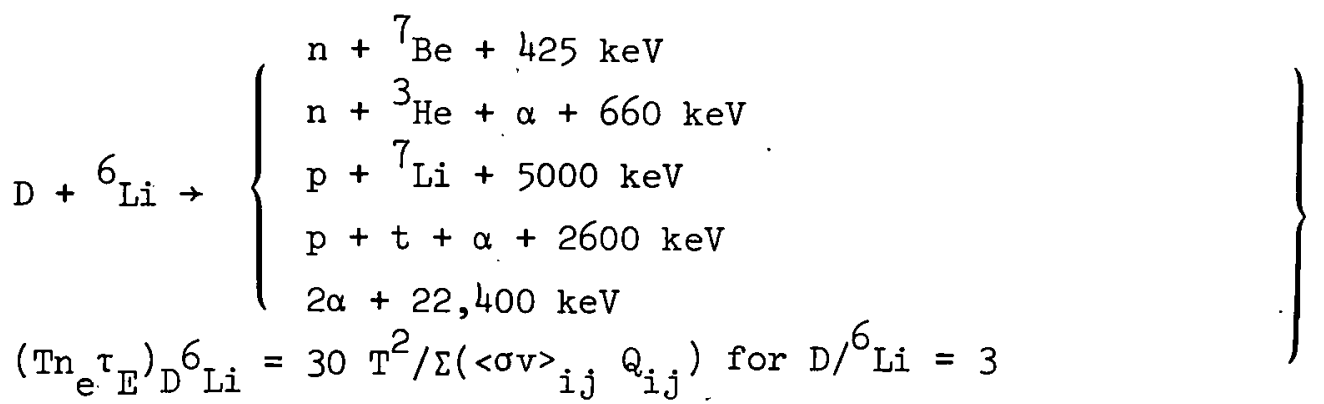

$$
\begin{aligned}
& \mathrm{p}+{ }^{1 I_{\mathrm{B}}} \rightarrow 3 \alpha+8700 \mathrm{keV}
\end{aligned}
$$

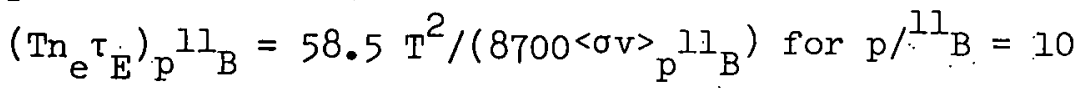

Figure 1 illustrates the temperature dependence of the ignition parameter for the various fusion fuels. The appropriate $\langle\sigma v\rangle$ values are taken from the advanced fuels reactivity code of McNally and Sharp [5]. The ignition curves for $D T, D^{3} \mathrm{He}$ and $D^{6} \mathrm{Li}$ do not include the $D+D$ reaction contributions which would increase the reactivity and lower the respective ( $\operatorname{Tn} \tau_{E}$ ) $I$ values for these fuels. This is especially true in case $(7)$ for $D^{6} \mathrm{Li}$ where deuterium is taken to be three times the ${ }^{6}{ }_{\text {Li }}$ abundance. Also, catalyzed burning of in situ generated $\mathrm{T}$ and ${ }^{3} \mathrm{He}$ would lower these three curves still further. Ash or impurity buildup, as well as early reaction product losses (occurring at $E>\frac{3}{2} \mathrm{~T}$ or $\tau<\tau_{E}$ ), would raise all curves somewhat. The "classical" fusion fuel DT has the lowest ( $\left.\operatorname{Tn}_{\mathrm{e}}{ }_{\mathrm{E}}\right){ }_{\mathrm{I}}$ curve and hence would have the highest power density for given $B^{2} B^{4}$. It may be too reactive in large systems in the range $\mathrm{T}<80 \mathrm{keV}$; thus, it may be important to evaluate the advanced fuels with this aspect in mind as well as considerations of tritium inventory, first wall damage and $14 \mathrm{MeV}$ neutron radiation damage. To attain the same power density with the advanced fuel reactors as with DT fuel at $T<80 \mathrm{keV}$, the advanced fuel reactors would need larger values of $\beta^{2} B^{4}$. 
Catalyzed DD fueled fusion reactors have an ignition parameter only about 10 times higher than pure DT at $10 \mathrm{keV}$, not 100 times as is commonly implied.

Should DT plasmas burn best at $\mathrm{T}=100-300 \mathrm{keV}$ the catalyzed $D D$ and "cleaner" $D^{3}$ He fueled reactors [6] would have a real competitive economic advantage as well as have comparable power densitjes. The more advanced fuels $\mathrm{p}^{6} \mathrm{Li}, \mathrm{p}^{11} \mathrm{~B}$ or ${ }^{3} \mathrm{He}^{3} \mathrm{He}$ would require a significantly larger $\beta^{2} B^{4}$ value in this temperature range. Recent studies suggest that catalyzed $\mathrm{DD}, \mathrm{DD}, \mathrm{D}^{6} \mathrm{Li}$, and $\mathrm{D}^{3} \mathrm{He}$ can operate in principle as steady state reactors provided $\beta>20 \%, n_{e}{ }^{\tau} i^{2} \times 10^{15} \mathrm{~cm}^{-3} \mathrm{sec}$, and $\mathrm{T}>50 \mathrm{keV}[6-8]$.

If the various experimental loss dependences are known as a function of $T$, the appropriate curve for each loss can be superposed on Figure 1. For example, the bremsstrahlung limited loss curve $\left(\operatorname{Tn}_{e} \tau_{L}\right)_{B}$ is for $\mathrm{T}_{\mathrm{e}}=\mathrm{T}_{i}$ :

$\left(\operatorname{Tn} e^{\tau}\right)_{B}=10^{15} \frac{3}{2}\left[n_{e}+\alpha_{i j}\left(n_{i}+n_{j}\right)+n_{x}\right] /\left[2\left(\Sigma z_{\ell}^{2} n_{\ell}+0.006 n_{e} T\right)\right]$, and for $n_{x}=0$ and DT or DD fuel the bremsstrahlung loss curve passes through the points $\left(1,10^{1}\right)$ and $\left(100, \sim 10^{4}\right)$ except for minor variations due to $z_{\ell}$ ( $\ell$ represents ions only) and high temperature relativistic effects. For the other fuel mixes the bremsstrahlung limited curve is lower by up to a factor of three. The allowable operating range for an ignited plasma lies below the loss curve(s) but above the gain curve $\left(\operatorname{Tn} \tau_{E}\right)_{I}$. Should $T_{e}$ be much less than $T_{i}$ the ignition curve is slightly lower by $\Sigma n_{\ell} / \Sigma n_{k}$ and the bremsstrahlung loss curve is higher by approximately $\sqrt{\mathrm{T}_{i} / \mathrm{T}_{\mathrm{e}}}$.

The simple magnetic mirror is expected to have a "quite low $\operatorname{Tn}{ }_{e} \tau_{\text {, }}$ value as a result of severe end losses and $\left(\operatorname{Tn} e^{\tau_{L}}\right)_{M}$ is about $\mathrm{T}\left(3 \times 10^{10} \mathrm{~T}^{3 / 2}\right.$ log $\left.\mathrm{R}\right) \cdot 10^{10} \mathrm{~T}^{5 / 2}$ fur a $2 / 1$ magnet1c mirror containing deuterium tuel ions. 'linis straight line curve intersects the points $\left(100,10^{1}\right)$ and $\left(1000,3 \times 10^{3}\right)$ on Fig. 1 and hence falls well below the ignition curve for any fuel. Thus, for an ignition plasma the magnetic mirror losses must be grossly reduced as in the Ion-layer or proton E-layer [9] or other reversed field mirror [10], or the mirror connected bumpy torus [11]。 At this time the fuel feed mechanisms and transport loss mechanisms are essentially unknown for these potential reactor configurations. 
III. THE FUSION ENERGY MUTIPLICATION FACTOR, $k$

The operation of nuclear fission reactors involves an important factor defining criticality called the neutron multiplication factor, $k$ [4]. There is a somewhat analogous factor which may be applied to nuclear fusion reactors and this section makes a first attempt at defining $\mathrm{k}$ for nuclear fusion reactors. By replacing "neutrons" by "energy" one can transfer some of the fission concepts to fusion analogies and an effective energy multiplication factor can be defined which is basically a measurement of ignition for $\mathrm{k}=I$ and prompt criticality or thermal runaway for $k>1$ (buildup of reactive $T$ and ${ }^{3}$ He may be analogous to delayed neutrons). It may prove very beneficial to delineate more exactly the presently used definition of $k$ for the fusion case as future plasmas approach ignition conditions. Present plasmas have $\mathrm{k}$ values which, while increasing substantially as experiments are improved, are at present less than $10^{-3}$.

In the event of a thermal runaway the nuclear burn undergoes an instability (when $k=1$ ), through a thermal runaway (when $k>1$ ), to a stable equilibrium at the burning or operating temperature (when $k$ reverts back to 1 ). Figure 2 illustrates schematically the thermal runaway of a radiation dominated, closed, pulsed DT burn. Other energy and particle losses will shift the burning or operating temperature down to lower temperatures. For a fixed fuel mix the burning temperature is stable, i.e., it has a negative temperature coefficient. The operating temperature is unstable to fuel mix perturbations, i.e., it has an important positive density coefficient, which must be feedback controlled.

The $k$ for fission reactors is defined as $k=f \eta \varepsilon p$, where $f$ is the neutron thermal utilization factor or the fraction of thermal neutrons which induce fissions. $n$ is the average number of fast neutrons produced by fission per thermal neutron. $\varepsilon$ is the fast fission factor due to suprathermal neutrons inducing fission reactions and $\varepsilon$ is then slightly larger than unity. $p$ is the resonance escape probability due to the loss of fast neutrons by nonfission (and usually resonance) capture processes, and $\mathrm{p}$ is always less than unity. 
The fusion "energy multiplication factor $k$ " is defined by the

$\frac{\mathrm{d}}{\mathrm{dt}}\left(\Sigma\left(\frac{3}{2}\right) \mathrm{n}_{\mathrm{k}} \mathrm{T}_{\mathrm{k}}\right)=(\mathrm{k}-1) \frac{\sum\left(\frac{3}{2}\right) \mathrm{n}_{\mathrm{k}} \mathrm{T}_{\mathrm{k}}}{\tau_{\mathrm{E}}}$

which has the exponential solution for $k$ and $\tau_{E}$ taken as constants $\Sigma\left(\frac{3}{2}\right) n_{k} T_{k}=\left(\Sigma\left(\frac{3}{2}\right) n_{k} T_{k}\right)_{0} e^{(k-1) t / \tau} E$

For $\mathrm{k}>1$ the plasma energy content grows exponentially in time, for $\mathrm{k}=1$ the stored energy is at an equilibrium which may be stable or unstable, and for $\mathrm{k}<1$ the energy content of the plasma decays exponentially or quenches. $k$ and $\tau_{E}$ may actually be complex functions of $n$ and $T$ so the analogy to the fission case is not exact.

A generalized form of this power density equation is

$$
\begin{aligned}
\frac{d}{d t}\left(\Sigma\left(\frac{3}{2}\right) n_{k} T_{k}\right) & =P_{D T}+P_{S I D E}+P_{E X T}+P_{B P}+P_{N E}+P_{C}-P_{E S C}-\frac{\Sigma\left(\frac{3}{2}\right) n_{k} T_{k}}{\tau_{L}} \\
& =(k-1) \frac{\sum\left(\frac{3}{2}\right) n_{k} T_{k}}{\tau_{L}}
\end{aligned}
$$

giving

$\mathrm{k}=\left(\frac{{ }^{2} \mathrm{P}_{\mathrm{DT}}}{\sum\left(\frac{3}{2}\right) \mathrm{n}_{\mathrm{k}} \mathrm{T}_{\mathrm{k}}}\right)\left(1+\frac{\mathrm{P}_{\mathrm{STDE}}+\mathrm{P}_{\mathrm{FXT}}}{\mathrm{P}_{\mathrm{DT}}}\right)\left(1+\frac{\mathrm{P}_{\mathrm{BP}}+\mathrm{P}_{\mathrm{NE}}+\mathrm{P}_{\mathrm{C}}}{\mathrm{P}_{\mathrm{DT}}+\mathrm{P}_{\mathrm{SIDE}}+\mathrm{P}_{\mathrm{EXT}}}\right)\left(1-\frac{\mathrm{P}_{\mathrm{ESC}}}{\Sigma \mathrm{P}_{+}}\right)$

and, analogous to the fission reactor case, we define the tour terms as $k=f \eta \varepsilon p$. Note that $k=f\left(\tau_{E}, n, T_{i}, T_{e}\right)$ except in a narrow sense.

The various power expressions are defined as $\mathrm{P}_{\mathrm{DT}}=$ fusion power density due to DT thermal reactions; $P_{S I D E}=$ fusion power density due to side thermal reactions (e.g., DD, TT, $\mathrm{D}^{3} \mathrm{He}$ ); $\mathrm{P}_{\text {EXT }}=\mathrm{P}$ due to external feed of energy (e.g., injected beams, ohmic heating, $\mathrm{ECH}$, etc.); $\mathrm{P}_{\mathrm{BP}}$, $\mathrm{P}_{N F_{1}}$, and $\mathrm{P}_{\mathrm{C}}$ are fast or suprathermal power terms due to beam-plasma or suprathermal second generation reactions and nuclear elastic (and in some cases nuclear inelastic), and hard Coulomb collisions which promote fuel ions to suprathermal energies; and $\mathrm{P}_{\mathrm{ESC}}$ represents direct or early alpha particle (or other charged fusion reaction products) escape, i.e., losses due to large particle orbits intersecting walls or being otherwise lost at $\mathrm{E}>\left(\frac{3}{2}\right) \mathrm{T}$ and/or $\tau<\tau_{\mathrm{E}^{*}} \quad \sum \mathrm{P}_{+}$is the sum of 
all positive power terms. In the case of advanced fusion fuels $f, n, \varepsilon$ and $\mathrm{p}$ would be defined relative to the leading fusion reaction, e.g., for DD $\mathrm{f} \rightarrow \tau_{L} \mathrm{P}_{\mathrm{DD}} / \Sigma\left(\frac{3}{2}\right)_{\mathrm{n}_{\mathrm{k}}} \mathrm{T}_{\mathrm{k}}$ and the $\mathrm{DT}$ and $\mathrm{D}^{3} \mathrm{He}$ are the important side reactions.

The "energy thermal utilization factor $f$ " defines the efficiency of the alpha particles from DT thermonuclear reactions in supporting the plasma energy content. It has a simple form as follows:

$$
\begin{aligned}
f & =\tau_{L} P_{D T} /\left(\Sigma\left(\frac{3}{2}\right)_{n_{k}} T_{k}\right) \\
& =P_{D T} / P_{\text {LOSS }} \\
& =\operatorname{Tn} e^{\left.\tau_{L}<\sigma v\right\rangle}{ }_{D T}{ }_{D T} / 12 T^{2} \text { for pure DT and } T_{i}=T_{e} \\
& =\left(\operatorname{Tn} i^{\tau_{L}}\right) /\left(T n_{e} \tau_{E}{ }^{\prime} I\right.
\end{aligned}
$$

which is to be evaluated at the experimental temperature $\mathrm{T}$.

Table I compares the energy thermal utilization factor $f$ for several experimental plasmas (see DIRECT column). The very low $f$ values for present devices $\left(\lesssim 2 \times 10^{-4}\right)$ indicate that this is the dominating influence in the attainment of a fusion energy multiplication factor $\mathrm{k} \geq 1$ for ignition.

The "fast fusion factor $\varepsilon$ " measures the contribution of suprathermal reactions to the energy balance. These suprathermal ions may be energetic injected fuel ions, second-generation fuel ions, or knock-on fuel ions (produced by short-range Coulomb collisions or nuclear elastic collisions of fuel ions with highly energetic fusion reaction products). Eventually the unreacted suprathermal ions merge into the thermal distribution. The second generation fuel ions originate primarily in DD side reactions such as $D+D \rightarrow p+t(1000 \mathrm{keV})$ or $\mathrm{n}+{ }^{3} \mathrm{He}(800 \mathrm{keV})$. $\mathrm{P}_{\mathrm{BP}} /\left(\mathrm{P}_{\mathrm{DT}}+\mathrm{P}_{\mathrm{SIDE}}\right)$ may approach or exceed unity in high temperature plasmas [12]. At electron temperatures approaching $100 \mathrm{keV},\left(\mathrm{P}_{\mathrm{NE}}+\mathrm{P}_{\mathrm{C}}\right) /$ $\left(\mathrm{P}_{\mathrm{DT}}+\mathrm{P}_{\mathrm{SIDE}}\right)$ may represent a significant fast fusion contribution. The macroscopic effect of nuclear elastic collisions has been considered in Ref. [8], but the proper way to treat these is as microscopic or individual suprathermal fuel ion events.

It should be noted that for externally driven systems (ohmic heating, beams, $\mathrm{RF}, \mathrm{ECH}$, etc.) at low temperatures (or low $\operatorname{Tn}_{\mathrm{e}} \tau_{\mathrm{l}}$ values) 
$\mathrm{P}_{\mathrm{EXT}} / \mathrm{P}_{\mathrm{DT}}$ may be very large and $\mathrm{k} \rightarrow 1$ for a steady state, non-ignited plasma; however, in a truly ignited system $\mathrm{k}$ would remain at or above unity when $P_{\text {EXT }} \rightarrow 0$. A truly economic burn would have $P_{\text {EXT }}$ very small or zero, otherwise one is dealing with a driven fusion burner with a large $P_{E X T}$ and hence large circulating power. We consider here only ignited cases for which eventually $\mathrm{P}_{\text {EXT }} \rightarrow 0$. Thus, the "energy increment factor $\eta^{\prime \prime}$ due to side thermal reactions at low temperatures is nearly unity, i.e., $\mathrm{P}_{\mathrm{SIDE}}<<\mathrm{P}_{\mathrm{DT}}$ unless there is a significant thermal runaway.

The "resonance escape probability $p$ " measures the direct or high energy losses of the energy of charged fusion reaction products and $p$ is less than unity. Such losses at $E>3 / 2 \mathrm{~T}$ and/or $\tau<\tau_{E}$ may occur as a result of direct collisions with the first wall, charge exchange, escape through the divertor region, etc. For pellet fusion $p$ would include neutron energy losses (and $Q=Q_{n}+Q_{+}$). A set of coupled particle conservation equations must also be included.

\section{EXPERIMENTAL STATUS AND PROSPECTS}

Table I gives experimental results from the MIT Alcator [13], the ORNL ORMAK [14], the Kurchatov T-10 [15], the Princeton PLT [16], the Fontenay-Aux-Roses TFR [17], the LLL 2XII-B [18], the ORNL DCX-1 [19], and the FEC MIGMA [20]. The present status of plasma experiments are clearly far short of ignition feasibility, whether measured by direct comparison of the $i$ value, $i . e .$, the ratio of experimental 'In $e^{\tau} \mathrm{l}$ to the ignition ( $\operatorname{Tn} e_{E}{ }_{E}$ ) values at constant $T$ (the energy utilization factor $f$ ), or indirectly in terms of $f^{*}$, the shortest distance to the nearest ignition ( $\left.\operatorname{Tn}_{E}{ }_{E}\right)_{I^{*}}$ (as discussed in the Appendix).

Table II lists the "quantum jumps" which have occurred in the past 18 years as new devices and new physics and technology have emerged. Note that both toroidai devices and magnetic mirrors have exhibited" dramatic improvements as measured by either $f$ or $\mathrm{f}_{10}^{*}$. Thus, tori have advanced by a factor of $10^{4}$ (or $10^{4}$ ) whereas magnetic mirrors have been improved by 200 (or 70 ) in $f$ (and $f_{10}^{*}$ ). Both devices still require major improvements in the experimentally achieved $\operatorname{Tn}_{e}{ }^{\dot{\tau}} \mathrm{L}$ values to attain an $f$ value near unity。 
The five tokamaks and the 2XII-B mirror device listed in Table I emphasize large power pulsed heating technologies (large ohmic heating currents and/or intense neutral beam injection). Such approaches pose potential deleterious gas loading and first wall power loading problems which must be overcome to permit the $>1000$ extrapolations to the ignition requirement.

The steady-state DCX-1 magnetic mirror experiment utilized modest beam power ( $\nu 10 \mathrm{~mA}$ of $600 \mathrm{keV} \mathrm{H}{ }_{2}^{+}$). Attempts were made to achieve an exponential or vacuum buildup of the fast ion density (exponentiation occurs when the plasma trapping rate exceeds the charge exchange loss rate) which, if successful, would have given about a three-thousandfold increase of density provided ECH (electron cyclotron heating) were used to reduce the stopping power of the cold electrons. The energetic protons were confined for $\tau_{p}$ up to $150 \mathrm{sec}$; however, the highly organized proton orbits in DCX-1 drove a severe negative mass instability which prevented attainment of the exponential condition and eventually the experiment was terminated. The 2XII-B mirror experiment did achieve exponential density buildup but, because of the extremely large charge exchange loss cross section at the low beam energies, required about $300 \mathrm{~A}$ (eq.) of injected neutral deuterium atoms into the 5-liter volume.

The multi-MeV MIGMA mirror experiment presently uses $3 \mathrm{MeV} \mathrm{D}_{2}^{+}$ injection and will attempt exponential buildup, as well as Lorentz trapping, and may ascertain the severity of instabilities in a well spread ion velocity distribution. Exponentiation appears much more favorable at these very high ion energies (especially for protons) because of the millionfold reduction of charge exchange losses compared to the 2XII-B case. If instabilities are surmountable, it appears very likely that intense $\mathrm{ECH}$ will be required to permit long ranging exponentiation or Lorentz trapping buildup in devịces using only modest in.jection currents $(\sim \mathrm{l} \mathrm{mA})$. The simple magnetic mirror devices may not allow economic fusion power unless the ends are stoppered in some way or one goes to the beam-driven fusion-fission option or the beam-driven, large circulating power pure fusion devices. 
The history of controlled fusion research reveals that major experimental progress has been made (see Table II). Much of this progress is due to the development of very intense energetic neutral beams of hydrogen and deuterium atoms. Expectations are high for near-term existing device experiments on PLT, TFR, T-10, and a new ORNL ISX (Impurity Study Experiment), as well as on the next generation device experiments on Princeton!s TFTR, the Kurchatov's T-20, and the LLL TMX devices. The author also feels that the prospects for exponential and Lorentz trapping buildup are worthy of further study [9]. ACKNOWLEDGEMENTTS

The author is indebted to Nermin Uckan, J. F. Clarke, D. L. Jassby, J. M. Dawson, and especially J. D. Callen for very helpful comments. 


\section{APPENDIX}

In order to evaluate the shortest distance from the experimental $T_{x} n_{x}{ }^{2} x_{x}$ to the DT ignition curve $T_{I} n_{I}{ }_{E I}$, multiply the $T$ abscissa of an $n \tau$ vs $T$ curve by $n_{I} \tau_{E I}$ and the $n \tau$ ordinate by $T_{I}$ and evaluate the shortest distance as

$$
\begin{aligned}
d & =\sqrt{\left(T_{I} n_{e I} \tau_{E I}-T_{I} n_{e x} \tau_{L X}\right)^{2}+\left(n_{I} \tau_{E I}\right)^{2}\left(T_{I}-T_{x}\right)^{2}} \\
& =\left(\operatorname{Tn}_{e} \tau_{E}{ }^{\prime} I \sqrt{\left(1-\frac{n_{e x} \tau^{2} L_{x}}{n_{e I}{ }^{\tau} E I}\right)^{2}+\left(I-\frac{T_{x}}{T_{I}}\right)^{2}}\right.
\end{aligned}
$$

In the general case one has for DT when $T_{i}=T_{e}$ and there are no impurities

$$
\left(\operatorname{Tn}_{e} \tau_{E}\right)_{I}=\frac{12 T_{I}^{2}}{\left\langle\sigma v{ }_{D T} T_{+}\right.}
$$

where $Q_{+}=3520 \mathrm{keV}$. This equation then gives an exact expression for d which should be used as one approaches ignition since ignition may occur at any temperature within certain limits (e.g., bremsstrahlung losses in a DT plasma give a minimum $\mathrm{T}_{\mathrm{I}}$ of about $4.5 \mathrm{keV}$ and a maximum $\mathrm{T}_{I}$ of about $700 \mathrm{keV}$ in the case of $\mathrm{T}_{i}=\mathrm{T}_{e}$ and optically thin plasmas). For a simple evaluation in terms of the nearest $\left(T n_{e} \tau_{E}\right)_{*}$ value take $T_{T} \sim 10 \mathrm{keV}$ and $n_{\text {eI }}{ }^{\top}$ EI $\sim 3 \times 10^{14} \mathrm{~cm}^{-3} \mathrm{sec}$. Defining $\mathrm{f}_{10}^{*}$ as $\mathrm{Tn} \mathrm{e}^{\tau} \mathrm{L}^{\prime}$ $\left(d+\operatorname{Tn}_{e^{\tau}{ }_{L}}\right)$ gives
$\mathrm{f}_{10}^{*}=\operatorname{Tn}_{e^{\tau}}{ }_{L}^{\prime}\left(3 \times 10^{15}\right.$

Tables I and II tabulate this "nearest" energy utilization factor for a number of experimental plasma cases. $f_{10}^{*} \rightarrow 1$ as a maximum. 
TABLE I. EXPEFIMENTAL ACHIEVEMENTS IV PLASMA DEVICES AND COMPARISON

WITH SCIENTIFIC FEASIBILITY IGNITION REQUIREMENTS

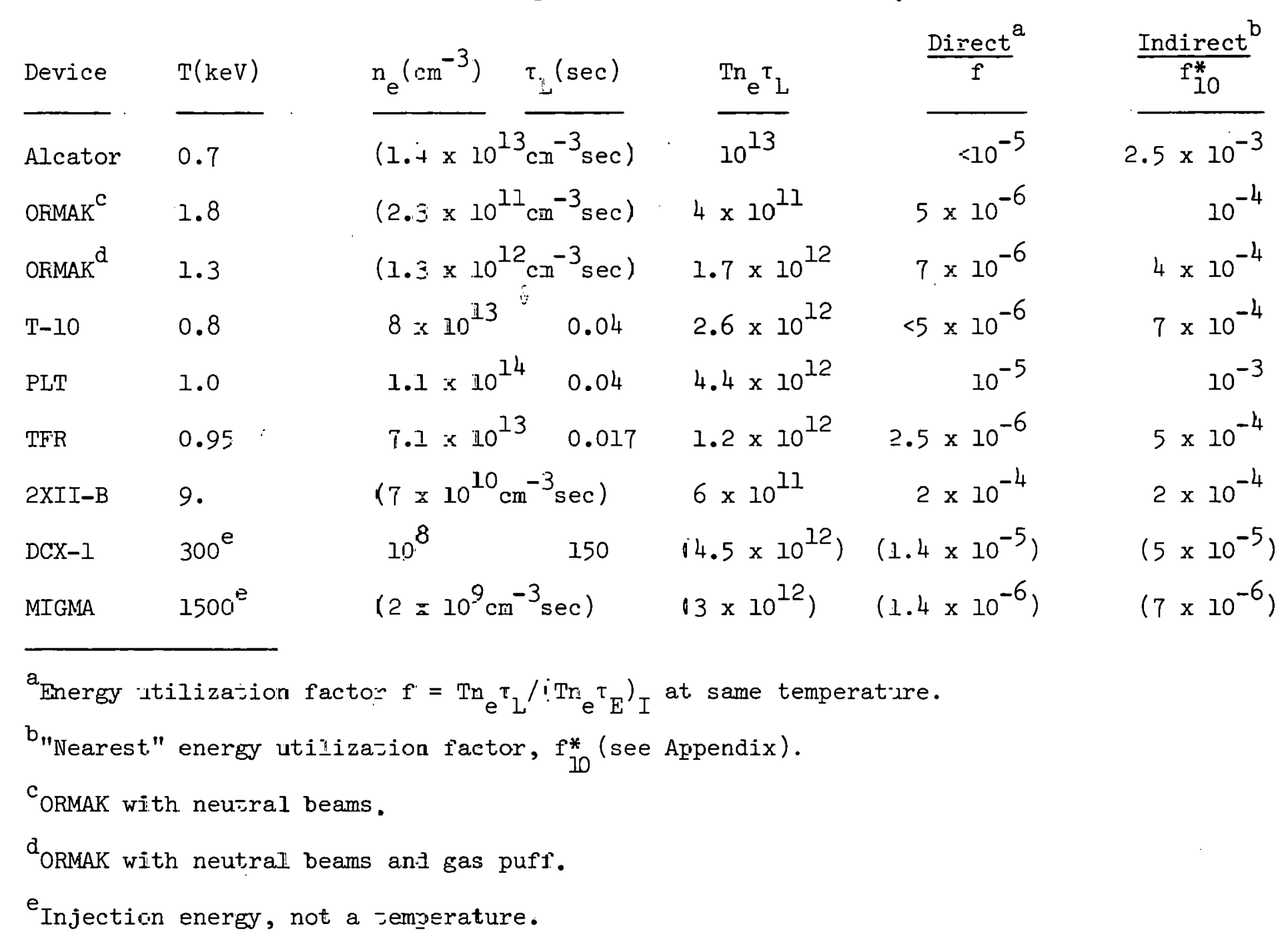


TABLE II. CHRONOLOGICAL JUMPS IN RELATIVE $T n_{e} \tau_{L}$ VALUES

\begin{tabular}{|c|c|c|c|c|c|c|c|c|}
\hline \multicolumn{9}{|l|}{ Type } \\
\hline Device & Year & Experiment & $\mathrm{T}(\mathrm{keV})$ & $\mathrm{e}^{\left(\mathrm{cm}^{-3}\right)}$ & $\tau_{L}(s)$ & $\operatorname{Tn}_{e}{ }^{\tau} L$ & $\mathrm{f}$ & $\mathrm{f}_{10}^{*}$ \\
\hline \multirow[t]{3}{*}{ Tori } & 1958 & Stellarator & $<0.1$ & $i^{10^{14}}$ & $10^{-4}$ & $<10^{9}$ & $<10^{-9}$ & $<3 \times 10^{-7}$ \\
\hline & 1958 & Tokamak T-3 & 0.5 & $5 \times 10^{13}$ & $7 \times 10^{-3}$ & $2 \times 10^{11}$ & $<2 \times 10^{-7}$ & $5 \times 10^{-5}$ \\
\hline & 1976 & Alcator & 0.7 & $(=.4$ & $\times 10^{13}$ ) & $1 \times 10^{13}$ & $<10^{-5}$ & $2.5 \times 10^{-3}$ \\
\hline \multirow[t]{3}{*}{ Mirrors } & 1958 & $D C X-1^{a}$ & $(300)^{b}$ & $10^{11}$ & 0.01 & $\left(3 \times 10^{11}\right)$ & $\left(1 \times 10^{-6}\right)$ & $\left(3 \times 10^{-6}\right)$ \\
\hline & 1956 & $D C X-1^{C}$ & $(300)^{b}$ & $10^{8}$ & 150. & $\left(4.5 \times 10^{12}\right)$ & $\left(1.4 \times 10^{-5}\right)$ & $\left(5 \times 10^{-5}\right)$ \\
\hline & 1976 & 2XII-B & 9. & $(7$ & $\left.x 10^{10}\right)$ & $6 \times 10^{11}$ & $2 \times 10^{-4}$ & $2 \times 10^{-4}$ \\
\hline
\end{tabular}

$a_{\text {With }}$ carbon arc as localized dissociator of injected $\mathrm{H}_{2}{ }^{+}$ions.

${ }^{\mathrm{b}}$ Injection energy, not a temperature.

With very low background gas density. 
Fig. 1. The ignition parameter $\left(\operatorname{Tn}_{e}{ }^{\tau} E^{\prime} I\right.$ vs kinetic temperature $T$ with $\mathrm{T}=\mathrm{T}_{i}=\mathrm{T}_{\mathrm{e}}$

Fig. 2. Schema illustrating radiation dominated, closed, pulsed, pure DT burn. The ignition temperature is unstable and the plasma will quench below $T_{I G N}$ if the external power is turned off', or undergo a thermal runaway above $\mathrm{T}_{I G N}$ independent of $\mathrm{P}_{\text {EXT }}$. The burning or operating temperature will be lower in the presence of additional energy and/or particie 1 ถsse.s or a.sh huididu. 


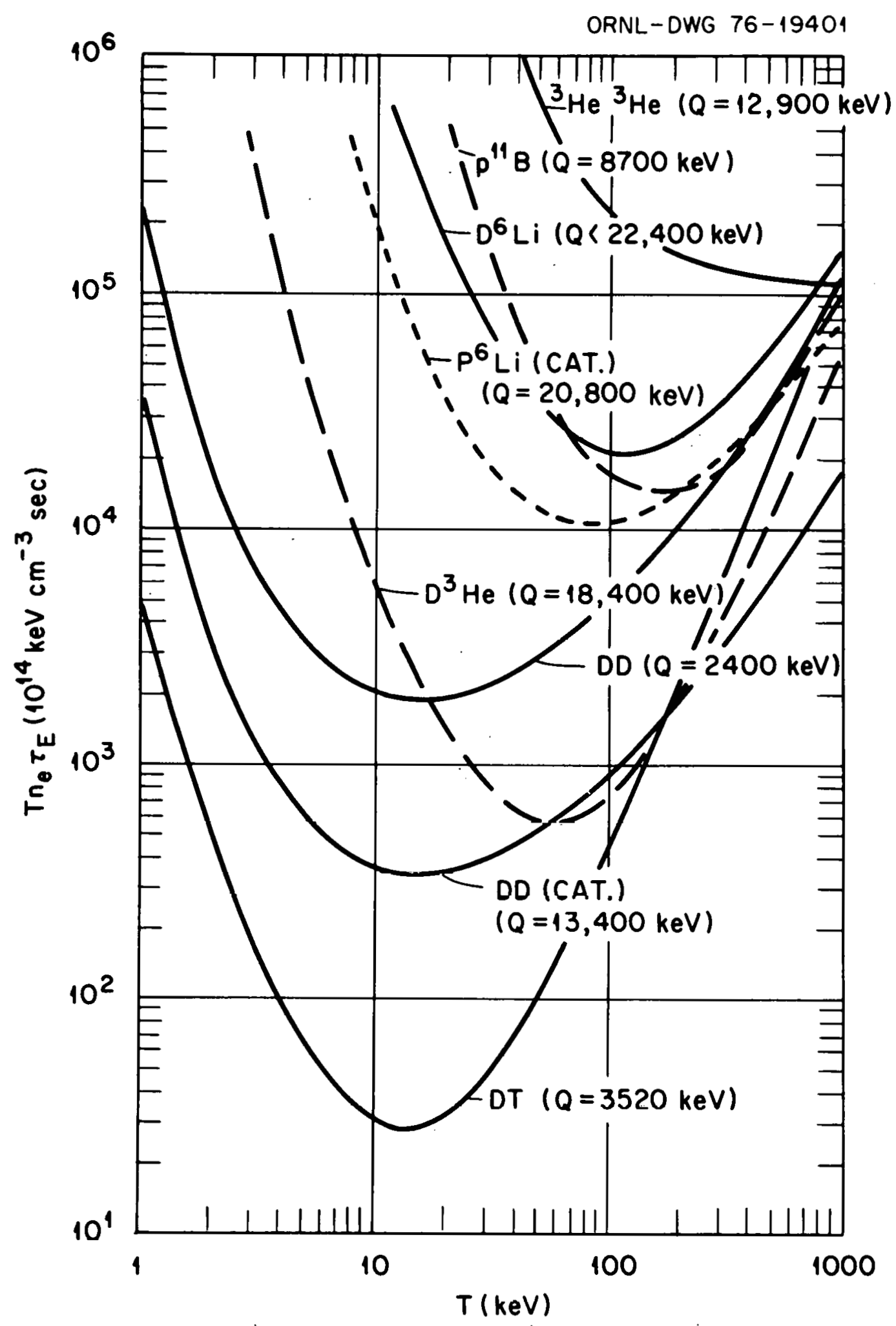

Fig. 1. The ignition parameter $\left(\mathrm{Tn}_{e} \tau_{\mathrm{E}}\right) \mathrm{I}$ vs kinetic temperature $\mathrm{T}$ with $\mathrm{T}=\mathrm{T}_{i}=\mathrm{T}_{\mathrm{e}}$. 
DRNL-OWG 74-9411

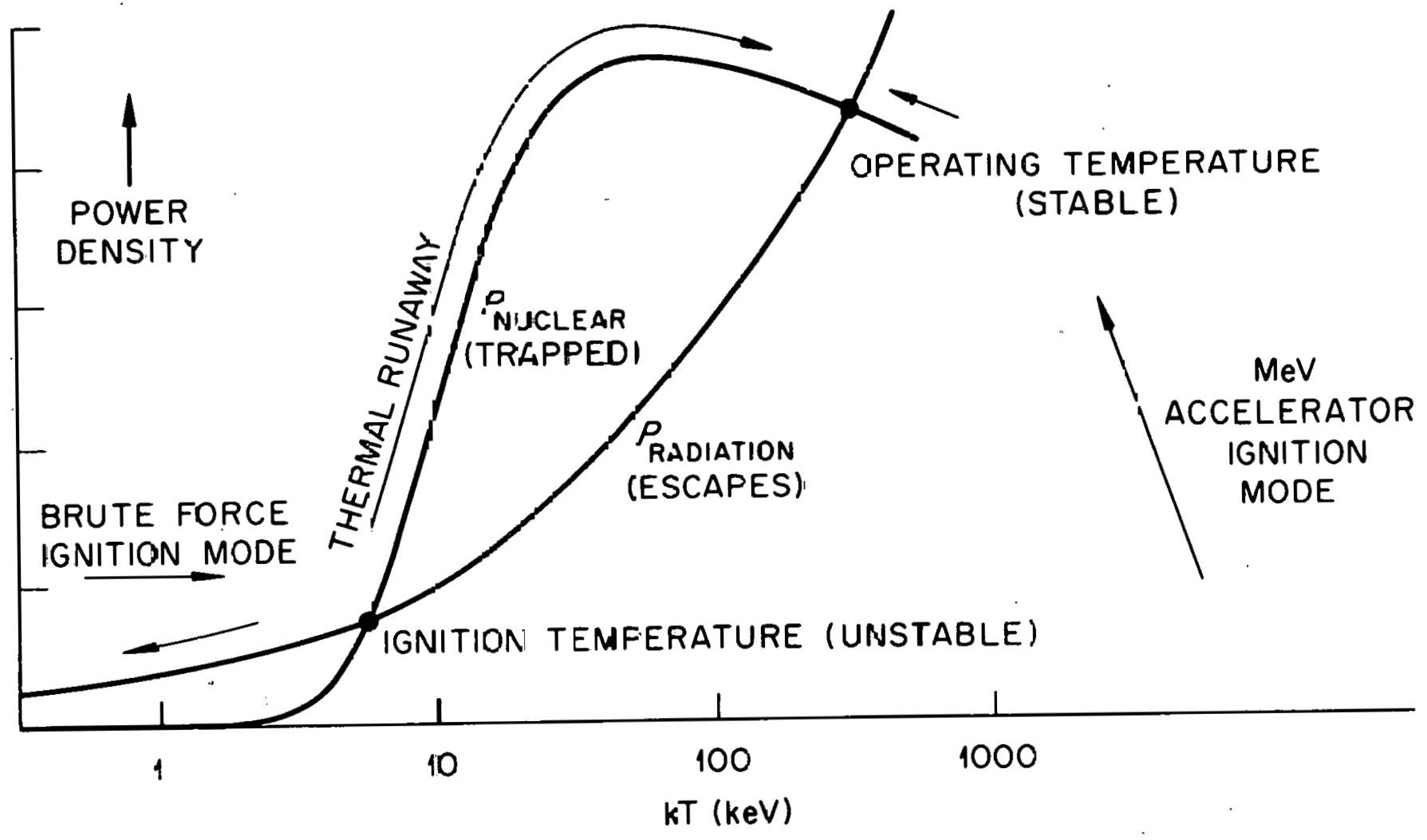

Fig. 2. Schema illistrating radiation dominated, closeć, pulsed, pure DT burn. The ignition temperature is unstable an the plasma will quench below $\mathrm{T}_{\text {IGN }}$ if the external power is turned of $f$, or undergo a thermal runaway above $\mathrm{T}_{\text {IGN }}$ independent of $\mathrm{P}_{\text {EXT }}$. The burning or operating temperajure will be lower in the presence of additional emergy and/or particle losses or ash buildup. 


\section{REFERENCES}

* Research sponsored by the Energy Research and Development Administration under contract with Union Carbide Corporation.

[1] LAWSON, J.D., Proc. Phys. Soc. Lond. B 70 (1957) 6.

[2] MCNALLY, Jr., J. RAND, SHARP, R. D., Nucl. Fusion 16 (1976) 868.

[3] MCNALLY, Jr., J. RAND, IAEA-SM-170/49 in Nuclear Data in Science and Technology II (1973) 41.

[4] GLASSTONE, S., EDLUND, M. C., The Elements of Nuclear Reactor Theory, D. Van Nostrand, Inc. New York (1952).

[5] MCNALLY, Jr., J. RAND, SHARP, R. D., unpublished data (1976).

[6] MCNALLY, Jr., J. RAND, SHARP, R. D., Bull. Am. Phys. Soc. 21 (1976) 1163.

[7] MCNALLY, Jr., J. RAND, Proc. Sixth IEEE Symposium on Engineering Problems of Fusion Research (1976) 1012.

[8] MCNALLY, Jr., J. RAND, Proc. Conf. on Nuclear Cross Section and Technology, NBS Special Publication 425 (1975) 683.

[9] MCNALLY, Jr., J. RAND, "Simplified Approach to Attaining a Proton

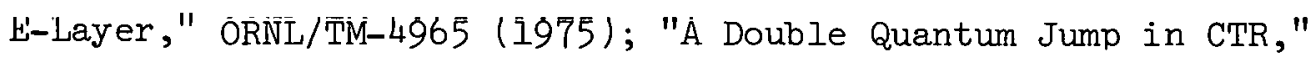
ORNL/TM-4967 (1975).

[10」 CONDIT, W. C., FOWLER, T. K., POST, R. F., "Status Report on Mirror Alternatives," UCRL-52008 (1976).

[II] MCALEES, D. G., UCKAN, N. A., BETTIS, E. S., HEDRICK, C. L., JAEGER, E. F., NELSON, D. B., OWEN. L. W., ROBERTS, J. F., SANTORO, R. T. , SPONG, D. A., WATTS, H. L., YEH, H. T., LIDSKY, L. M., EHST, D. A., HERRING, J. S., KAPLAN, D. L., PANT, A., POTOK, R. E., "The ELMO Bumpy Torus Reactor (EBTR) Reference Design," ORNL/TM-5669 (1976). 
[12] See MILEY, G. H., Fusion Energy Conversion, American Nuclear Society (1976). See also JASSBY, D. L., TOWNER, H. H., Nucl. Fusion 16, (1976) 911.

[13] APGAR, E., COPPI, B., GONDHALEKAR, A., HELAVA, H., KOMM, D., MARTIN, F., MONTGOMERY, B., PAPPAS, D., PARKER, R., OVERSKEI, D., LAHA-CIN-35/A5, Berchtesgaden (1976).

$\lceil 14\rceil$ LYON, J. F., Oak Ridge National Laboratory, private communication (December 1976): See also BERRY, L., BUSH, C. E., CALLEN, J.'D., COLCHIN, R. J., DUNLAP, J. L., EDMONDS, P. H., ENGLAND, A. C., FOSTER, C. A., HARRIS, J. H., HOWE, H. C., ISLER, R. C., JAHNS, G. L., KETTERER, H. E., KING, P. W., LYON, J. F., MIHALCZO, J. T., MURAKAMI, M., NEIDIGH, R. V., NEILSON, G. H., PARE, V. K., SHAEFFER, D. L., SWAIN, D. W., WILGEN, J. B., WING, W. R., ZWEBEN, S. J., IAEA-CN35/A4-1, Berchtesgaden (1976).

[15] BERLIZOV, A. B., BOBROVSKII, G. A., BAGDASAROV, A. A., VASIN, N. L., VERTIPOROKH, A. N., VINOGRADOV, V. P., VINOGRADOVA, N. D., GEGECHKORY, N. M., GORBUNOV, E. P., DNESTROVSKII, YU. N., ZAVERJAEV, V. S., IZVOZCHIKOV, A.'B., LUK'ANOV, S. YU., LYSENKO, S. E., MAXIMOV, YU. S., NOTKIN, G. E., FETROV, M. Г., FOГKOV, G. N., RAZUMOVA, K. A., ETRELKOV, V. S. SHCHEGLOV, D. A., IAEA-CN-35/Al, Berchtesgaden $(1976)$.

[16] GROVE, D., ARUNASALAM, V., BOL, K., BOYD, D., BRETZ, N., BRUSATI, M., COHEN, S., DIMOCK, D., DYLLA, F., EAMES, D., EUBANK, H., FRAENKEL, B., GIRARD, J., HAWRYLUK, R., HINNOV, E., HORTON, R., HOSEA, J., 
REFERENCES CONTINUED

HSUAN, H., IGNAT, D., JOBES, F., JOHNSON, D., MAZZUCATO, E. , MESERVEY, E., SAUTHOFF, N., SCHIVELL, J., SCHMIDT, G. , SMITH, R., STAUFFER, F., STODIEK, W., STRACHEN, J., SUCKEWER, S., VON GOELER, S., YOUNG, K., IAEA-CN-35/A2, Berchtesgaden (1976).

[17] TFR Group, IAEA-CN-35/A3, Berchtesgaden (1976).

[18] COENSGEN, F. H., CLAUSER, J. F., CORRELL, D. L., CUMMINS, W. F., GORMEZANO, C., LOGAN, B. G., MOLVIK, A. W., NEXSEN, W. E., SIMONEN, T. C., STALLARD, B. W., TURNER, W. C., IAEA-CN-35/Cl, Berchtesgaden (1976).

[19] DUNLAP, J. L., HASTE, G. R., NEILSEN, C. E., POSTMA, H., REBER, L. H., Phys. Fluid 9 (1966) 199.

[20] MIGMA Lab News, Fusion Energy Corporation (September 1976). 
THIS PAGE WAS INTENTIONALLY LEFT BLANK 
INTERNAL DISTRIBUTION

ORNL/TM-5766

1. J. D. Callen

2. J. F. Clarke

3. R. A. Dory

4. G. G. Kelley

5. 0. B. Morgan

6. M. W. Rosenthal

7-31. J. Rand McNally, Jr.

32-34. Laboratory Records Department

35. Laboratory Records, ORNL - RC

36. Y-12 Document Reference Section

37-38. Central Research Library

39. Fusion Energy Division I.ibrary

40. Fusion Energy Division Reports Office

41. ORNL Patent Office

\section{EXTERNAL DISTRIBUTION}

42. Plasma Physics Library, Plasma Physics Laboratory, Princeton Univ., Forrestal Campus, P.0. Box 451, Princeton, NJ 08540

43. Controlled Thermonuclear Research Library, Lawrence Livermore Laboratory, P.0. Box 808, Livermore, CA 94550

44. Q Division Library, Los Alamos Scientific Laboratory, P.0. Box 1663, Los Alamos, NM 87544

45. Controlled Thermonuclear Research Library, c/o Weston M. Stacey, Jr., Argonne National Laboratory, 9700 S. Cass Ave., Argonne, IL 60439

46. CTR Computer Center, c/o Dr. John Killeen, Lawrence Livermore laboratory, P.0. Box 808, Livermore, CA 94550

47. Librarian, Culham Laboratory, U.K. Atomic Energy Authority, Abingdon, Oxon, OX14 3DB, United Kingdom

48. Ruth Lengye, Blbliorhek, Max-Planck Institut für Piasmaphysik, 8046 Garching bei München, Federal Republic of Germany

49. Library, Centre de Recherches en Physique des Plasmas, 21 Avenue des Bains, 1007, Lausanne, Switzerland

50. A. M. Dupas, Documentation S.I.G.N., Départment de la Physique du Plasma et de la Fusion Controlée, Association EURATOM-CEA sur 1a Fusion, Centre d'Etudes Nucléaires, BP 85 Centre Du TRI 38041 Grenoble Cedex (France)

51. Bibliothèque, Service du Confinement des Plasmas, C.E.A., B.P. No. 6, 92, Fontenay-aux-Roses (Seine) France

52. Library, International Centre for Theoretical Physics, Trieste, Italy

53. Library, Laboratorio Gas Tonizzati, Frascati, Italy

54. V. E. Ivanov, Physical-Technical Institute of the Ukranian Academy of Sciences, Sukhumi, U.S.S.R.

55. L. M. Kovrizhnikh, Lebedev Institute of Physics, Academy of Sciences of the U.S.S.R., Leninsky Prospect 53, Moscow, U.S.S.R.

56. Prof. Dshumber G. Lominadze, Academy of Sciences of the Georgian SSR, 8 Dzerzhinski St., 38004, Tbilisi, USSR

57. Library, Inst. for Plasma Physics, Nagoya Univ., Nagoya, Japan 464 
58. Library, FOM-Institut voor Plasma-Fysica, Rijnhuizen, Jutphaas, Netherlands

59. Plasma Physics Group, Department of Engineering Physics, Australian National University, P.0. Box 4, Canberra A.C.T. 2600, Australia

60. Thermonuclear Library, Japan Atomic Energy Research Institute, Tokai, Naka, Ibaraki, Japan

61. Dr. D. G. McAlees, Exxon Nuclear Co., Inc., Research \& Technology Laser Enrichment Department, 2955 George Washington Way, Richland, WA 99352

62. CTR Reading Room, c/o Prof. D. W. Kerst, Dept. of Physics, Sterling Hal1, Univ, of Wisconsin, Madison, WI 53706

63. CTR Reading Room, c/o Prof. I. B. Bernstein, Yale Univ., 200 Mason Laboratory, Dept. of Engineering \& Applied Science, New Haven, CT 06510

64. Center for Plasma Physics and Thermonuclear Research, c/o D. W. Ross, Phÿsics Dept., Univ. of Texas, Austin, TX 78712

65. CTR Reading Room, c/o Prof. B. D. Fried, Physics Dept., Univ. of California, Los Angeles, CA 90024

66. CTR Reading Room, c/o Prof. David C. Montgomery, Physics \& Astronomy Dept., Univ. of Iowa, Iowa City, IA 52240

67. Magneto-Fluid-Dynamics Library, c/o Dr. Harold Grad, Courant Inst. of Math. Sci., New York Univ., 251 Merccr St., New York, NY 10012

68. CTR Reading Room, c/o Prof. Allan N. Kaufman, Physics Dept., Univ. of California, Berkeley, CA 94720

69. Dr. David A. Dingee, Fusion Programs, Batelle-Northwest, Batelle Boulevard, Richland, WA 99352

70. CTR Reading Room, c/o Prof. C. S. Liu, Dept. of Physics and Astronomy, Univ. of Maryland, College Park, MD 20742

71. CTR Reading Room, c/o Prof. T. Kammash, 103 Research Admin. Bldg., N. Campus, Univ. of Michigan, Ann Arbor, MI 48105

72. CTR Reading Koom, c/o Dr̈. Ravi N. Sudan, Phillips Hal1, Cornel1 Univ., Ithaca, NY 14850

73. Prof. Marshal1 N. Rosenbluth, Institute for Advanced Study, Princeton, N.T 08540

74. CTR Reading Room, c/o Prof. R. Gross, Plasma Research Lab., Columbia Univ., New York, NY $10 n 27$

75. CTR Reading Room, c/o Prof. Roy Gould, California Inst. of Tech., M.S. 116-81, Pasadena, CA 91125

76. Dr. Nicholas A. Kra11, Science Applications, Inc., P.0. Box 2354, 1200 Prospect St., La Jolla, CA 92037

77. CTR Reading Room, c/o Dr. Jay P. Boris, Plasma Physics, Naval Research Laboratory, Washington, DC 20390

78. Professor A. Simon, Depl. ul Mechanical \& Aerospãce Scionces, University of Rochester, Rochester, NY 14627

79. CTR Library, c/o Dr. Alan F. Haught, United Technologies Research Labs, East Hartford, CT 06108

80. Dr. H. K. Forsen, Exxon Nuclear Co., Inc. 777-106th Avenue, NE, C-000777, Bellevue, WA 98009

81. Dr. George Vahala, Physics Dept., College of William \& Mary, Williamsburg, VA 23185

82. Dr. Robert E. Price, Division of Magnetic Fusion Energy, G-234, Energy Research and Development Administration, Washington, D. C. 20545 
83. Dr. R. C. Davidson, Division of Magnetic Fusion Energy, G-234, Energy Research and Development Administration, Washington, D. C. 20545

84. Dr. Oscar P. Manley, Division of Magnetic Fusion Energy, G-234, Energy Research and Development Administration, Washington, D. C. 20545

85. Mr. E. E. Kintner, Division of Magnetic Fusion Energy, G-234, Energy Research and Development Administration, Washington, D. C. 20545

86. Dr. L. D. Pearlstein, L-388, Lawrence Livermore Laboratory, P.0. Box 808, Livermore, CA 94550

87. Dr. J. P. Friedberg, Los Alamos Scientific Laboratory, Los Alamos, NM 87544

88. Dr. David J. Rose, Dept. of Nuclear Engineering, MIT, Cambridge, MA 02139

89. Dr. Gareth E. Guest, General Atomic Co., P.0. Box 81608, San Diego, CA 92138

90. Dr. Claude Mercier, Service du Theorie des Plasmas, Centre d'Etudes Nucléaires, Fontenay-aux-Roses (seine) France

91. Dr. J. B. Taylor, Culham Laboratory, UKAEA, Abingdon, Oxon, OX14 3DB, United Kingdom

92. Dr. D. Pfirsch, Institute for Plasma Physics, 8046 Garching bei München, Federal Republic of Germany

93. Dr. V. D. Shafranov, I. V. Kurchatov Inst. of Atomic Energy, 46 Ulitsa Kurchatova, P.0. Box 3402, Moscow, U.S.S.R.

94. Dr. A. Rogister, Institute for Plasma Physics, KFA, Postfach 1913, D-5170, Jülich 1, Federal Republic of Germany

95. Dr. J. G. Cordey, Culham Laboratory, UKAEA, Abingdon, Oxon, OX14 3DB, United Kingdom

96. Dr. David Baldwin, L-388, Lawrence Livermore Lab., P.O. Box 808 , Livermore, CA 94550

97. CTR Reading Room, c/o Prof. Bruno Coppi, Dept. of Physics, MIT, Cambridge, MA 02130

98. Dr. Harold P. Furth, Princeton Plasma Physics Lab., Princeton Univ., P.0. Box 451, Princeton, NJ 08540

99. Dr. Paul H. Rutherford, Princeton Plasma Physics Lab., Princeton Univ., P.0. Bux 451, Princeton, NJ 08540

100. Dr. Herbert H. Woodson, Dept. of Electrical Engineering, Univ. of Texas, Austin, TX 78712

101. Research \& Technical Support Div., Oak Ridge Operations, Energy Research and Development Administration, P.O. Box E, Oak Ridge, TN 37830

102-128. Technical Information Center, Energy Research and Development Administration, Oak Ridge, TN 37830 